\title{
Practical natural ventilation performance metric based on thermal autonomy for sustainable building design
}

\author{
Kyosuke Hiyama ${ }^{1, *}$, and Liwei Wen ${ }^{2}$ \\ ${ }^{1}$ School of Science and Technology, Meiji University, 2148571 Kanagawa, Japan \\ ${ }^{2}$ School of Civil Engineering, GuangZhou University, 510006 Guangzhou, China
}

\begin{abstract}
Natural ventilation is an essential component in sustainable building design. However, successfully incorporating it remains difficult because the utilizable amounts of ambient energy resources differ according to project conditions such as ambient climates. Moreover, lack of a metric that could encourage an architect to design a proper plan and façade for natural ventilation at the schematic design stage is being recognized as a barrier to successful achievement of natural ventilation. An inappropriate plan and façade would make it impossible to make thorough considerations for successful implementation of natural ventilation at the later design stages. To encourage even the architects without special expertise in natural ventilation, the metric should be as simple as possible to evaluate the achieved natural ventilation design intuitively and rationally. This paper proposes net Thermal Autonomy as a modified metric of Thermal Autonomy, which cannot easily evaluate the achievement level because the applied weather data significantly influence the calculated value. In the proposed metric, a universal threshold covering climate factors is available by applying net time, while the outdoor condition suitable for natural ventilation is used in the denominator. The practicality of the proposed metric is examined through parametric building energy simulations and analyses.
\end{abstract}

\section{INTRODUCTION}

Architectural design needs to consider regional architectural characteristics in order to realize highly effective utilization of natural energy in pursuit of maximized building energy and environmental performance. However, realization of designs that secure maximum utilization of available ambient energy resources is difficult through conventional design methods because they examine the energy savings ratio based solely on the energy consumption of baseline buildings. As the amount of available ambient energy differs in accordance with ambient climate conditions, it is difficult to put a clear target on the energy savings ratio. Consequently, new metrics have recently been proposed to evaluate the application of technics utilizing natural energy resources. For example, Daylight Autonomy and related metrics have become common as dynamic daylight metrics [1-3]. The Daylight Autonomy metric is defined as "the percentage of annual daytime hours that a given point in a space is above a specified illumination level." Thanks to significant innovations in information technology and increases in computing power, annual-based simulations have become common in building performance evaluations [4-6].

Natural ventilation, as well as daylighting, is being viewed as an inevitable design element in the effort to maximize the usage of natural energy resources surrounding a building [7-11]. Several indexes [12] have been proposed to evaluate the potential. At the beginning of the building project, the potential can be used to aid the decision-making as to whether the natural ventilation strategy should be implemented. The number of naturally ventilated buildings has been increasing and actual related performances have been reported [13, 14]. However, most of the evaluations presented are based on analyses over a short period and evaluations are rarely conducted over a period of one year. One of the reasons for this discrepancy is the fact that no common metric that can evaluate the effects based on annual investigations exists in natural ventilation designs. An energy saving ratio is often used $[15,16]$, but determining a reasonable target ratio is difficult. As the potential amount of ambient energy resource differs with project conditions, such as ambient climate, the energy saving percentage that is adequate to judge whether a successful natural ventilation design has been implemented is difficult to stipulate. Predicted percentage of dissatisfied (PPD) is also used to check the achieved thermal comfort in naturally ventilated buildings [17, 18]. PPD weighted criteria are proposed in EN $15251[19,20]$, as well as the "percentage outside the range" and "degree hours criteria" indexes, for long term evaluation of the general thermal comfort conditions. These criteria effectively evaluate the achieved indoor thermal environment in naturally ventilated buildings when they are applied for natural ventilation design. However, the index mainly refers to

\footnotetext{
* Corresponding author: hiyama@meiji.ac.jp
} 
the thermal comfort achieved indoor. The objective of this study is to maximize utilization of ambient resources. In this context, an index is necessary to evaluate the ventilation performance to specify whether the air exchange amount is sufficient to exhaust excess internal heat generation. The combined use of such an index to evaluate ventilation performance and a comfort index to evaluate achieved indoor environment is essential for successful natural ventilation implementation. At present, the natural ventilation performance is typically checked based only on whether the air change rate in a specific condition can reach a target amount (e.g., 3 ACH [21]) that is considered to be a sufficient air exchange amount for natural ventilation based on the architect's or engineer's experience.

Although some architects and engineers have been performing building energy simulations and optimizing natural ventilation strategies [22, 23], no valid metric has obtained a consensus to evaluate the achievement level. In particular, placing a clear goal in terms of building design remains difficult, while the realized thermal comfort level in naturally ventilated buildings is being actively discussed $[24,25]$. In this context, a metric for evaluating the level of natural design achievement, especially at the early stage of building design, is essential. In addition, an evaluation of Daylight Autonomy is required to measure the level of daylight design achievement in Leadership in Energy \& Environmental Design (LEED) [26]. A clear threshold, over $55 \%$, is set in LEED for spatial daylight autonomy. This helps even non-experts to check their daylighting design achievement level. As well as a façade design is critical for the daylighting design, a building plan and façade, mainly designed by an architect at the schematic design stage, are critical to devise successful natural ventilation strategies. Inappropriate plans and façades make it impossible to design proper natural ventilation implementations and operations at the later design stages. In this context, a metric to encourage even an architect without expertise in natural ventilation into an appropriate design is critical, especially at the early design stages. For example, the effective area sufficient for windows or vents should be determined and the driving force sufficient to move the ventilated air should be designed to ensure design flexibilities at the later stage when the detailed natural ventilation design is performed. Natural ventilation should be implemented considering other passive heating or cooling designs [27] as well as advanced HVAC operations [28]. Even a complex facility integrating daylighting and natural ventilation functions may be installed [29]. It sometimes includes conflicting goals between achieving indoor environment quality and energy saving. Therefore, the design flexibilities are essential to achieve the complex goals. Although natural ventilation and daylighting are driven by different physics concepts with different complexities in their principles, the metric should be as simple as the Daylight Autonomy metric to evaluate the achieved natural ventilation design intuitively and rationally. Because the implementation would result in significant engineering difficulties at the later design stage [30], a simple metric to facilitate communication between architects and engineers at the early stage to lead the architects in appropriate design plans and façades is essential. Consequently, the new "Thermal Autonomy" metric [31] has been proposed as such a metric that can evaluate natural ventilation effects. The metric, which has been developed to evaluate the utilization level of available ambient energy resources, is defined as the "percent of a year that occupants feel thermally comfortable through passive means only." In [31], an hour of discomfort and the degree of discomfort is also discussed. As one of the metrics for natural ventilation designs, the metric has been used in several case studies $[32,33]$. Design methods using this metric are also proposed in [31], with the expectation that they will facilitate architects' understanding through visualizing daily or seasonal changes of the effects of the passive means. The metric is highly useful in terms of communication between architects and environmental designers. However, as stated in [31], more benchmarking studies are necessary in order for the metric to be applied universally for sustainable building designs. Considering the above discussion, this paper firstly reviews the metric. Then, a new metric that can be upgraded in order for it to be used in more wide-spread practical designs is determined. This includes allocation of a universal threshold in order to have even nonsimulation experts understand and utilize the metric in their architectural design.

As the American Institute of Architects points out in "An Architect's Guide to Integrating Energy Modeling in the Design Process [34]," the role of energy analysis differs depending on the design process. The objective of Design Performance Modeling, as they define it, is to analyze the sensitivity of the design variables on energy and environmental performance at an early design phase. Thermal Autonomy may therefore be a valid metric for sensitivity analysis. Meanwhile, an energy-consumptionbased evaluation of the energy performance of the building is still required in Building Energy Modeling for reviewing compliance with design policies at a later phase, including optimization of energy consumption compared with a baseline.

\section{THERMAL AUTONOMY}

Thermal Autonomy is defined as "the percent of occupied time over a year where a thermal zone meets or exceeds a given set of thermal comfort acceptability criteria through passive means only" [31].

$\mathrm{TA}$ is the percentage of the year that the room temperature falls within the comfort range without HVAC systems (Equations 1 and 2).

$$
\begin{aligned}
& f_{i n, j}=1 \text {, when } \theta_{i n}^{\text {limit, lower }}<\theta_{i n, j}<\theta_{\text {in }}^{\text {limit upper }} \\
& T A=\frac{\sum_{a}^{b} f_{i n, j} \cdot \text { time }_{j}}{\sum_{a}^{b} \text { time }_{j}} \times 100
\end{aligned}
$$

$f_{i n, j}$ : binary factor at time step $j$ ( 0 or 1 )

$\theta_{i n, j}:$ indoor temperature at time step $j$

$\theta^{\text {limit }}$ : lower or upper limit of the comfort range 


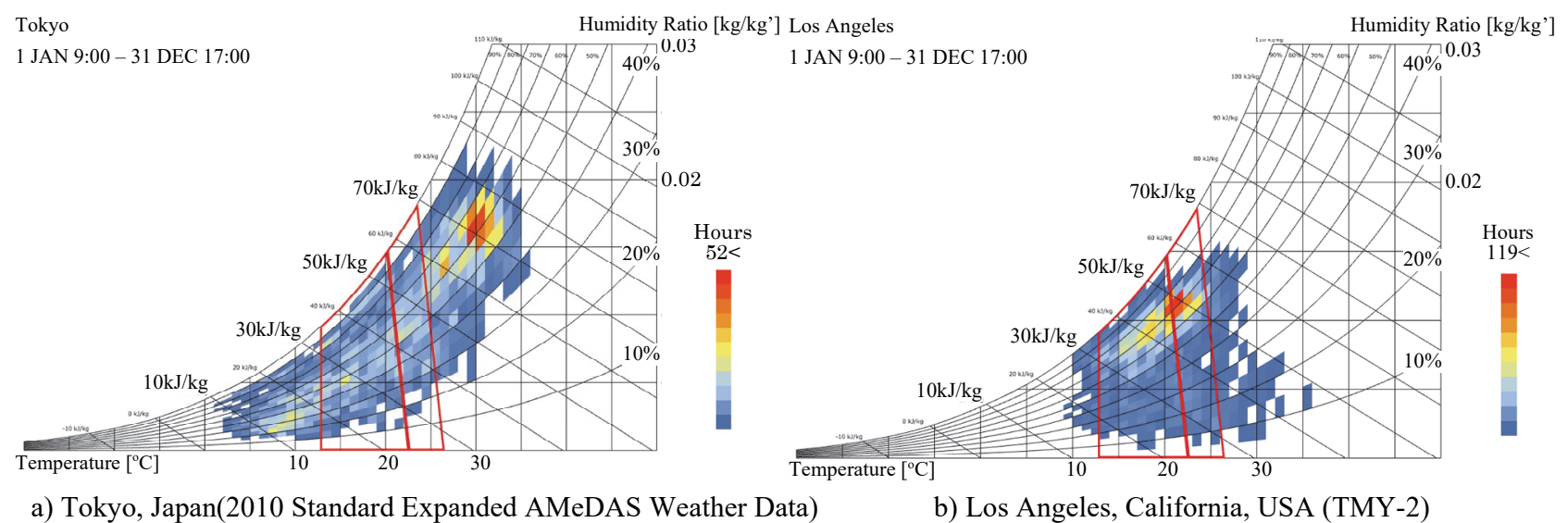

a) Tokyo, Japan(2010 Standard Expanded AMeDAS Weather Data)

b) Los Angeles, California, USA (TMY-2)

Figure 1. Psychrometric charts for Tokyo, Japan and Los Angeles, California, USA.

time $_{j}$ : time period at time step $j$

$a, b:$ start and end of occupied hour for evaluation

As was stated in [31], "thermal autonomy analysis gives rich visual feedback as to the diurnal and seasonal patterns of thermal comfort that an architectural proposition is expected to deliver." However, there are no clear instructions on how to understand the number TA itself. It is difficult to make a judgment using TA alone as to whether more examinations are necessary to improve the natural ventilation design. TA is influenced not only by the building design but also the climate conditions. For example, the TA value tends to be smaller in hot and humid climates because the period during which the outdoor air is suitable for natural ventilation is short. This means that the TA value itself includes information not only on the design aptitude but also the climate of the area in which the building is located. In this context, modification of the definition of TA is necessary in order to establish a clear target number that can indicate the levels of natural ventilation design achievement alone. This would enable designers and engineers to utilize TA as an effective metric for their decision-making by modifying their design to reach the target number.

\section{NET THERMAL AUTONOMY}

\subsection{Definition}

As stated above, it is necessary for decision-making to establish a clear target value that can measure the level of achievement reached by a designer or an engineer who has conducted thorough examinations in his/her natural ventilation design. However, it is difficult to establish a clear target value on the original TA because it is highly influenced by the applied weather data. The maximum value is limited by how suitable the climate conditions are for natural ventilation, e.g., the cooler a yearly climate condition is, the higher the TA value tends to be. In cases where the metric is used to measure the aspects of the building design itself, the maximum value should be the same in any building project. A value of $100 \%$ is easily understandable by nonsimulation experts. Consequently, this paper proposes the net Thermal Autonomy (nTA) metric as the percentage of time periods in which the indoor climate is comfortable without mechanical cooling as long as the outdoor air can be used to remove excess indoor heat generation (Equations 3, 4, and 5).

$$
\begin{aligned}
& f_{\text {in }, j}=1, \text { when } \theta_{\text {in }, j}<\theta_{\text {in }}^{\text {limit }, \text { upper }} \\
& f_{\text {out }, j}=1 \text {, when } \theta_{\text {out }, j}<\theta_{\text {out }}^{\text {limit upper }} \\
& n T A=\frac{\sum_{a}^{b} f_{\text {in }, j} \cdot \text { time }_{j}}{\sum_{a}^{b} f_{\text {out }, j} \cdot \text { time }_{j}} \times 100
\end{aligned}
$$

$f_{\text {in }, j}, f_{\text {out } j}$ : binary factor at time step $j$ ( 0 or 1 )

$\theta_{i n, j}:$ indoor temperature at time step $j$

$\theta_{\text {out }, j}$ : outdoor temperature at time step $j$ (alternative with enthalpy of outdoor air)

$\theta_{\text {in }}^{\text {limit, upper }}:$ upper limit of the comfort range

$\theta_{\text {out }}^{\text {limit,upper }}$ : upper limit of the comfort range (can be alternated with upper limit in enthalpy)

time $_{j}$ : time period at time step $j$

$a, b:$ start and end of occupied hour for evaluation

This definition is based on the following considerations. In the original definition of TA [31], occupied hours were simply used for the denominator followed by the definition of percentage outside the range in EN 15251, the European standard for thermal comfort performance. In the case study presented in the original paper, the TA reached $86 \%$ because it was studied under "California coastal climates that should not require building heating or cooling much of the year." In contrast, in a case study conducted under the climate condition of Tokyo Japan, where building require cooling in the hot and humid summer, the maximum $\mathrm{TA}$ is around $50 \%$ even in a scenario with relatively well-insulated façade and high amounts of natural ventilation. The number itself might lead a person to mistakenly surmise that the natural ventilation design is inappropriate comparing to the case in Los Angeles. However, the difference in the number is mainly caused by the aptitudes of the climate condition for natural ventilation operation. The psychrometric charts of the outdoor thermal condition using Ladybug tools on Grasshopper are shown in Figure 1. In Figure 1a (Tokyo, Japan), many hours are outside the comfort range where it is impossible to maintain 


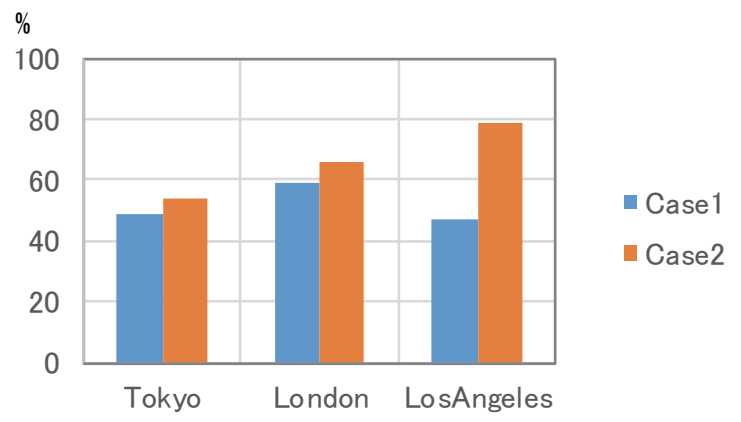

Figure 2. Thermal Autonomy (TA) in different climates.

comfortable indoor thermal conditions with natural ventilation alone. The percentage of the input data that are inside all comfort and passive strategy polygons is only $40 \%$. On the other hand, the percentage increases to $80 \%$ in Figure $1 \mathrm{~b}$ (Los Angeles, California, USA). The maximum values of TA are highly influenced by those percentages based on the weather data. Therefore, a thorough climate analysis is needed to deeply understand what exactly is meant by the TA value itself. Without such a process and an expert who analyzes climate data, misunderstandings may occur in the decision-making process as to whether the energy saving potential utilizing natural ventilation is fully achieved or not through discussion of natural ventilation designs including building plans, proportions, and specifications. Thus, this paper proposes that the sum of the occupancy hours while outdoor air is at a comfortable temperature be used as the net time while outdoor condition is suitable for natural ventilation. In other words, the summated value of the net time is used as the denominator for the proposed nTA calculation. Both drybulb temperature and enthalpy of outdoor air are commonly used to determine the suitability in operations of real buildings. The threshold should be set by a physical quantity used in each project. The time periods while the indoor climate is below the comfort lower limit are excluded from the numerator in the originally defined TA calculation. These time periods expand following increments in the appearance of cold weather conditions where heating is necessary. Such time periods can be reduced primarily by upgrading the insulation levels, while a natural ventilation strategy generally does not directly affect the time periods. The fluctuation of the time periods should not be included in discussions of the natural ventilation strategies. With these considerations in mind, all hours while the indoor temperature is below the upper limit of the comfort zone are included in the numerator of the nTA calculation such that the fluctuation of the hours due to the cold weather and insulation level does not affect the discussion of natural ventilation strategy. Thus, nTA can be utilized as a simple metric to evaluate the level of achievement for natural ventilation design.

\subsection{Case study}

A case study was performed to evaluate the practicality of the proposed nTA metric for natural ventilation design. Energy simulations to calculate the proposed nTA and the original TA metrics were performed with a same

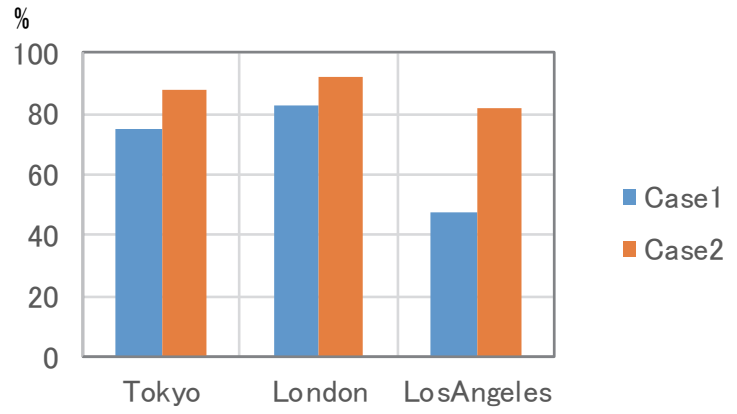

Figure 3. net Thermal Autonomy (nTA) in different climates.

building model using different weather data; specifically, Tokyo, Japan (AMeDAS Data); London, UK (IWEC data); and Los Angeles, USA (TMY-2 data). Case 1 is the base case that the mean natural ventilation rate is around 2 3 ACH. Case 2 is the case in which the more significant natural ventilation performances were observed by increasing the opening size 4 times as larger as those in Case 2. The weather data for London and Los Angeles represent a cold climate and a mild climate, respectively. The weather data for Tokyo represent a climate with a relatively precise schedule with the changing seasons - hot and humid in summer and dry and cold in winter. The sum of the hours that indoor air temperature is below comfort upper limits, $26{ }^{\circ} \mathrm{C}$ in this case study, was used as the numerator. The sum of the hours that outdoor air is available to remove the internal heat waste through natural ventilation was used as the denominator. In this study, the period during which the outdoor air temperature is below the representative comfort temperature of $24{ }^{\circ} \mathrm{C}$ was treated as the suitable outdoor climate condition for natural ventilation.

In Figure 2, the original TA values in Case 1 are shown. The TA values are around $50 \%$ in all locations. It is difficult to discuss whether the implemented natural ventilation design is appropriate or not at this stage as the TA value only reveals that the autonomous levels in terms of thermal comfort are the same among the three cases. A comparative investigation using another building model is therefore needed to discuss more factors. In Figure 2, the TA values in Case 2 are shown. Although increments in TA values are observed at all locations compared to those in Case 1, large differences among the TA values can also be observed. The increment in the TA value in Los Angeles is significant and the absolute value is clearly larger than the others. This means that setting a relatively large opening area is effective for a building in Los Angeles for successful natural ventilation implementation compared to those in Tokyo and London. In a mild climate area such as Los Angeles, the period during which the outdoor air temperature is suitable for natural ventilation is much longer than those in other climates. The percentage of hours when the outdoor air temperature is below $24{ }^{\circ} \mathrm{C}$ is $97 \%$ in Los Angeles, whereas it is $70 \%$ in Tokyo. However, the temperature or enthalpy difference between indoor air and outdoor air tends to be small owing to the mild weather condition. Thus, a large amount of outdoor air intake is necessary to sufficiently exhaust excess indoor heat generation in office buildings. 
In Figure 3, the proposed nTA values are shown. In Case 2 , all the nTA values are over $80 \%$ because sufficient amounts of outdoor air intake are guaranteed in all locations. Although more benchmark studies are required, $80 \%$ can be set as the universal threshold to evaluate the level of achievement of satisfied natural ventilation attempts. Additional studies are being planned, including validation using a real office building under construction in Japan. On the other hand, only the nTA value in London reaches the threshold in Case 1. This is caused from the fact that the demanded amount of outdoor intake is relatively low in cold climates. It also means that some upgrades in natural ventilation design will be required in other locations. In particular, significantly low nTA values below $50 \%$, such as Case 1 in Los Angeles in this study, will encourage architects and engineers to reconsider their strategies. A meaningful discussion is available with nTA value alone, whereas multiple energy simulations, yearly thermal maps, and climate analyses were necessary to result in the same decision-making in terms of natural ventilation opening area in cases with the original TA. In addition, a fixed nTA value threshold can enable non-simulation experts to achieve superior natural ventilation designs due to its understandability.

\section{CONCLUSIONS}

A practical metric for evaluating the level of natural ventilation design achievement, analogous to the Daylight Autonomy (DA) metric employed in LEED to evaluate the level of daylight design achievement, is necessary in architectural sustainable building design. On the premise that detailed natural ventilation designs should be implemented in the later design stages, communication between architects and engineers in the early design stages should be facilitated with a simple metric that can guide the architects to develop proper building plans and facades for successful natural ventilation implementation. The metric should have a universal threshold for the achievement level, such that the meaning of the value is easily understandable even by non-simulation experts such as architects without expertise in natural ventilation.

To this end, the new Thermal Autonomy metric that has been proposed as a candidate. The Thermal Autonomy metric and its graphical outputs are very useful in building design processes that attempt to increase the use of ambient energy resources. However, the metric requires thorough climate analysis and deep understanding to comprehend precisely what the calculated value means. Thus, this paper proposed a new metric, called the net Thermal Autonomy metric. The proposed metric modifies the original metric such that it can easily be used, even by non-simulation experts, without climate analysis. The sum of occupancy hours while the outdoor climate is at a comfort point is used as the denominator of the new metric. In this way, the climate factor is automatically included in the calculated value. This makes it possible to set a universal threshold value that can be applied to any building project under different climates. A case study on effective opening areas for natural ventilation application was also performed as an example. The results revealed that the level of natural ventilation achievement can be measured with the single new metric alone without a thorough climate analysis. In the example, decision-making in terms of sufficient opening area size could be achieved even under different climates by setting $80 \%$ as its universal threshold value. The numerator was also modified for all hours while the indoor temperature was below the upper limit of the comfort zone, such that the metric could be used simply to measure natural ventilation effects.

In a previous study [35], it was revealed that the target air change rate for successful natural ventilation application could be roughly discussed based on weather data and the estimated amount of combined internal heat generation. At the very beginning of building design, it should be determined whether the target air change rate can be obtained with the initial building proposal, such as building plans and specifications. It supports initialization of the building project such that a design that impossibly harnesses sufficient ambient energy resources is not produced. Further, the performance throughout a year should be checked by utilizing annual building energy simulations. nTA and its universal threshold proposed in this paper are useful at this stage. The achieved thermal comfort levels in naturally ventilated buildings should be simultaneously discussed during the design process. Increments in outdoor intake amount to maximize the usage of ambient energy resources may cause discomfort in the environment, such as cold draft problems. The combined use of some thermal comfort indexes with our proposed method should be considered in future studies.

However, even though the proposed metric alone may not be sufficient to evaluate the natural ventilation comprehensively, it can enhance communications between architects and engineers in the early design stages. This would guide the architects to develop proper building plans and facades to ease upcoming engineering difficulties in the later design stages.

\section{Appendix: Case study details}

The office model was created based on the floor plan and building specification of the wall layers in the guideline for ZEB design [36], representing a forthcoming Japanese office building standard. The typical floor plan and the building specifications are shown in Figure A1 and Table A1, respectively, whereas the simulation model is shown in Figure A2. In the model, a stack ventilation strategy is employed for the 2 nd and 3rd floors. Vents for the intake of outdoor flesh air are located at the window tops on the north and south façade. The ventilation air goes up through the void located at the center of the floor plan, and is exhausted through the vents located at the penthouse above the 5th floor. The vents at the penthouse are set equally on four orientations. The vents are opened from 7:00 to 20:00 when cooling is off, and the indoor air temperature is 


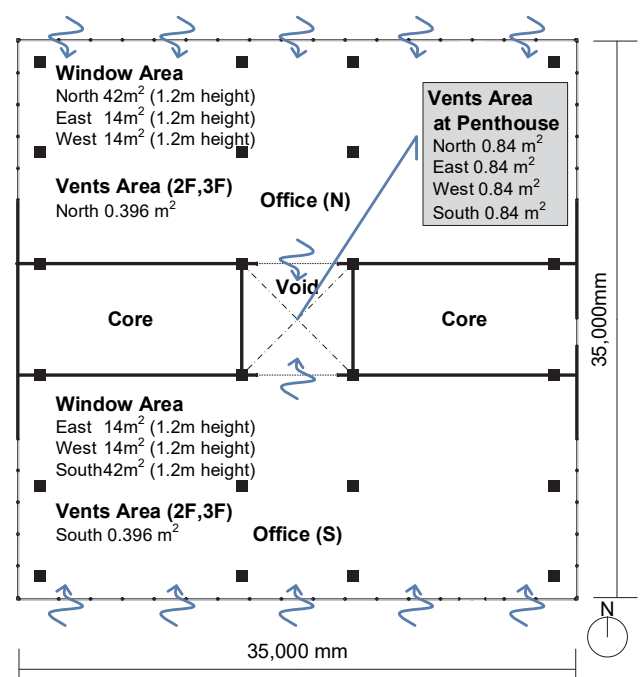

Figure A1. Typical floor plan of the office model.

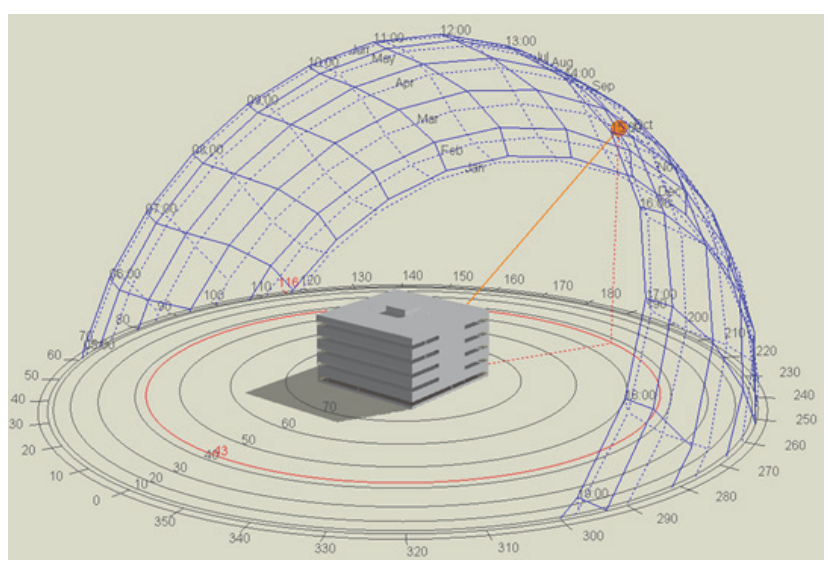

Figure A2. Simulation model.

Table A1. Building specifications and internal heat generation settings.

\begin{tabular}{|c|c|c|}
\hline \multicolumn{2}{|c|}{ Number of Stories } & $5+$ Penthouse for stack ventilation \\
\hline \multicolumn{2}{|c|}{ Floor height } & $4.0 \mathrm{~m}$ \\
\hline \multirow{4}{*}{$\begin{array}{c}\text { Wall } \\
\text { Materials }\end{array}$} & External walls & $\begin{array}{l}\text { Concrete } 150 \mathrm{~mm} \text {, XPS Extruded Polystyrene } 25 \mathrm{~mm} \text {, Gypsum Plasterring } 8 \mathrm{~mm} \\
\text { U value } 1.06 \mathrm{~W} / \mathrm{m}^{2}-\mathrm{K}\end{array}$ \\
\hline & Flat roof & $\begin{array}{l}\text { Concrete } 60 \mathrm{~mm} \text {, XPS Extruded Polystyrene } 50 \mathrm{~mm} \text {, Concrete } 150 \mathrm{~mm} \text {, Air gap, } \\
\text { Gypsum Plasterring } 8 \mathrm{~mm} \\
\text { U value } 0.54 \mathrm{~W} / \mathrm{m}^{2}-\mathrm{K}\end{array}$ \\
\hline & Internal floor & Concrete $100 \mathrm{~mm}$ \\
\hline & Windows & $\begin{array}{l}\text { Double ; (outer) LoE Clear } 3 \mathrm{~mm} \text {, Air } 10 \mathrm{~mm} \text {, Clear } 3 \mathrm{~mm} \text {; } \\
\text { U value } 1.91 \mathrm{~W} / \mathrm{m}^{2}-\mathrm{K} \text {, SHGC } 0.60 \\
\text { Aluminium window frame (with thermal break); U value } 5.01 \mathrm{~W} / \mathrm{m}^{2}-\mathrm{K}\end{array}$ \\
\hline \multirow{3}{*}{$\begin{array}{c}\text { Internal } \\
\text { Heat } \\
\text { Generation } \\
\text { (Office) }\end{array}$} & Metabolic & $\begin{array}{l}0.1 \text { person } / \mathrm{m}^{2}, 123 \mathrm{~W} / \text { person } \\
\text { Schedule } 7-(0.25)-8-(0.5)-9-(1.0)-12-(0.75)-14-(1.0)-17-(0.5)-18-(0.25)-19-(0)-7\end{array}$ \\
\hline & Office equipment & $\begin{array}{l}12 \mathrm{~W} / \mathrm{m}^{2} \\
\text { Schedule 7-(0.25)-8-(0.5)-9-(1.0)-12-(0.75)-14-(1.0)-17-(0.5)-18-(0.25)-19-(0.05)-7 }\end{array}$ \\
\hline & Lighting & $\begin{array}{l}10 \mathrm{~W} / \mathrm{m}^{2} \\
\text { Schedule 7-(1.0)-19-(0)-7 }\end{array}$ \\
\hline
\end{tabular}

above both $24{ }^{\circ} \mathrm{C}$ and the outdoor air temperature. Occupancy starts from 8:00. The natural ventilation begins operation an hour before the occupancy hour to remove heat from the room in cases where the indoor air temperature exceeds the comfort threshold during the night owing to internal heat generation and morning solar heat gain. Wind pressure, as well as stack effect, is also considered as the driving force for the natural ventilation. Wind pressure coefficients were set based on data in previous research [37]. Infiltration was modeled in the natural ventilation simulation. The airtightness level was set at an excellent level based on data from previous research [37]. The commercial software, Design Builder, with Energy Plus as an analysis solver, was used for the dynamic simulation.

For the comfort zone, the set of acceptability criteria defined based on an adaptive comfort standard in ASHRAE Standard 55 [38] is originally employed for the TA evaluation. However, the application of the adaptive comfort standard has a limitation. The standard is based on the data from naturally ventilated buildings without cooling and heating systems; therefore, more discussions are necessary to apply it directly to building designs equipped with sophisticated HVAC systems.
Natural ventilation equipment are only used during mild weather seasons and cooling systems are used during summer in most naturally ventilated buildings in Japan [13]. This study targets such buildings in which architects aim to achieve high-level performances, such zero-energy buildings (ZEBs). Therefore, a common comfort zone for HVAC design, air temperature between 22 and $26{ }^{\circ} \mathrm{C}$, is used in this paper. Temperatures of $26{ }^{\circ} \mathrm{C}$ and $22{ }^{\circ} \mathrm{C}$ are typically used for room air temperature set points for cooling and heating, respectively, in Japan. The thermal autonomy is calculated based on this comfort zone. At present, although air temperature is employed for the threshold to reflect real building design and operation, it can be substituted with thresholds in adaptive comfort models in cases where these sophisticated ideas are employed in real building operations.

\section{Acknowledgements}

This study was supported by the Institute of Science and Technology, Meiji University. 


\section{References}

1. Reinhart, C. F., Mardaljevic, J., Rogers, Z. Dynamic daylight performance metrics for sustainable building design. LEUKOS - Journal of Illuminating Engineering Society of North America, 2006, 3 (1), 7-31.

2. Bian, Y., Ma, Y. Analysis of daylight metrics of side-lit room in Canton, south China: A comparison between daylight autonomy and daylight factor. Energy and Buildings, 2017, 138, 347-354.

3. Lo Verso, V.R.M., Mihaylov, G., Pellegrino, A., Pellerey, F. Estimation of the daylight amount and the energy demand for lighting for the early design stages: Definition of a set of mathematical models. Energy and Buildings, 2017, 155, 151-165.

4. Castaldo, V.L., Pisello, A.L. Uses of dynamic simulation to predict thermal-energy performance of buildings and districts: A review. Wiley Interdisciplinary Reviews: Energy and Environment, 2018, 7(1), e269-n/a.

5. Reinhart, C.F., Walkenhorst, O. Validation of dynamic RADIANCE-based daylight simulations for a test office with external blinds. Energy and Buildings, 2001, 33(7), 683-697.

6. Schulze, T., Eicker, U. Controlled natural ventilation for energy efficient buildings. Energy and Buildings, 2013, 56, 221-232.

7. Oropeza-Perez, I., Østergaard, P.A. Potential of natural ventilation in temperate countries - A case study of Denmark. Applied Energy, 2014, 114, 520530 .

8. Oropeza-Perez, I., Østergaard, P.A. Energy saving potential of utilizing natural ventilation under warm conditions - A case study of Mexico. Applied Energy, 2014, 130, 20-32.

9. Zhai, Z., Mankibi, M.E., Zoubir, A. Review of Natural Ventilation Models. Energy Procedia, 2015, 78, 2700-2705.

10. Chenari, B., Dias Carrilho, J., Gameiro da Silva, M. Towards sustainable, energy-efficient and healthy ventilation strategies in buildings: A review. Renewable and Sustainable Energy Reviews, 2016, 59, 1426-1447.

11. Tong, Z., Chen, Y., Malkawi, A., Liu, Z. Freeman, R.B. Energy saving potential of natural ventilation in China: The impact of ambient air pollution. Applied Energy, 2016, 179, 660-668.

12. Campaniço, H., Soares, P.M.M., Hollmuller, P., Cardoso, R.M. Climatic cooling potential and building cooling demand savings: High resolution spatiotemporal analysis of direct ventilation and evaporative cooling for the Iberian Peninsula, Renewable Energy, 2016, 85, 766-776.

13. Nomura, M., Hiyama, K. A review: Natural ventilation performance of office buildings in Japan. Renewable and Sustainable Energy Reviews, 2017, 74 (Supplement C), 746-754.
14. Aflaki, A., Mahyuddin, N., Al-Cheikh Mahmoud, Z., Baharum, M.R. A review on natural ventilation applications through building façade components and ventilation openings in tropical climates. Energy and Buildings, 2015, 101, 153-162.

15. Elharidi, A.M., Tuohy, P.G., Teamah, M.A. The energy and indoor environmental performance of Egyptian offices: Parameter analysis and future policy. Energy and Buildings, 2018, 158, 431-452.

16. Daaboul, J., Ghali, K., Ghaddar, N. Mixed-mode ventilation and air conditioning as alternative for energy savings: A case study in Beirut current and future climate. Energy Efficiency, 2018, 11(1), 1330.

17. Lan, L., Tushar, W., Otto, K., Yuen, C., Wood, K.L. Thermal comfort improvement of naturally ventilated patient wards in Singapore. Energy and Buildings, 2017, 154, 499-512.

18. Hussain, S., Oosthuizen, P.H. Numerical investigations of buoyancy-driven natural ventilation in a simple three-storey atrium building and thermal comfort evaluation. Applied Thermal Engineering, 2013, 57(1), 133-146.

19. BSi, BS EN 15251 Indoor environmental input parameters for design and assessment of energy performance of buildings addressing indoor air quality, thermal environment, lighting and acoustics. in: Evaluation of the indoor environment and long term indicators, BSI publications, London, 2007.

20. Olesen, B.W. Revision of EN 15251: Indoor Environmental Criteria, REHVA Journal, 2012, 49 (4), 6-12.

21. Architectural_Institute_of_Japan, Natural Ventilation Design Handbook for Architects and Building Engineers. GIHODO SHUPPAN, 2017.

22. Vitale, V., Salerno, G. A numerical prediction of the passive cooling effects on thermal comfort for a historical building in Rome. Energy and Buildings, 2017, 157, 1-10.

23. Chen, X., Yang, H., Zhang, W. Simulation-based approach to optimize passively designed buildings: A case study on a typical architectural form in hot and humid climates. Renewable and Sustainable Energy Reviews, 2018, 82, 1712-1725.

24. de Dear, R.J., Brager, G.S. Thermal comfort in naturally ventilated buildings: Revisions to ASHRAE Standard 55. Energy and Buildings, 2002, 34(6), 549-561.

25. Emmerich, S.J., Polidoro, B., Axley, J.W. Impact of adaptive thermal comfort on climatic suitability of natural ventilation in office buildings. Energy and Buildings, 2011, 43(9), 2101-2107.

26. Nezamdoost, A., Van den Wymelenberg, K.G. Revisiting the Daylit Area: Examining Daylighting Performance Using Subjective Human Evaluations and Simulated Compliance with the LEED Version 4 Daylight Credit. Leukos, 2017, 13 (2), 107-123. 
27. Calautit, J.K., Hughes, B.R., Nasir, D.S.N.M. Climatic analysis of a passive cooling technology for the built environment in hot countries. Applied Energy, 2017, 186, 321-335.

28. Yu, T., Heiselberg, P., Lei, B., Zhang C., Pomianowski, M., Jensen, R. Experimental study on the dynamic performance of a novel system combining natural ventilation with diffuse ceiling inlet and TABS. Applied Energy, 2016, 169, 218229.

29. Taengchum, T., Chirarattananon, S., Exell, R.H.B., Kubaha, K. Chaiwiwatworakul, P. A study on a ventilation stack integrated with a light pipe. Applied Thermal Engineering, 2013, 50(1), 546-554.

30. Chen, X., Yang, H. A multi-stage optimization of passively designed high-rise residential buildings in multiple building operation scenarios. Applied Energy, 2017, 206, 541-557.

31. Levitt, B., Ubbelohde, M.S., Loisos, G., Brown, N. Thermal Autonomy as Metric and Design Process. in: Pushing the Boundaries: Net positive Buildings, SB13 Vancouver, Vancouver, 2013, pp. 47-58.

32. Wang, L.-S., Ma, P., Hu, E., Giza-Sisson, D., Mueller, G., Guo, N. A study of building envelope and thermal mass requirements for achieving thermal autonomy in an office building. Energy and Buildings, 2014, 78, 79-88.

33. Ma, P., Wang, L.-S., Guo, N. Maximum window-towall ratio of a thermally autonomous building as a function of envelope U-value and ambient temperature amplitude. Applied Energy, 2015, 146, 84-91.

34. AIA, An Architect's Guide to Integrating Energy Modeling in the Design Process. In: The American Institute of Architects, 2012, p. 8.

35. Hiyama, K., Glicksman, L. Preliminary design method for naturally ventilated buildings using target air change rate and natural ventilation potential maps in the United States. Energy, 2015, 89 (Supplement C), 655-666.

36. ZEB_Roadmap_Followup_Commitee, ZEB design guideline, in, 2017.

37. Orme, M., Liddament, M.W., Wilson, A. Numerical data for air infiltration and natural ventilation calculations. Air Infiltration and Ventilation Centre, 1998.

38. ASHRAE, ASHRAE Standard 55 - Thermal environment conditions for human occupancy. In: ASHRAE Inc., Atlanta, 2010. 